\title{
Synthesis and Structural Characterizations of Carbon Nanotubes Enveloped with Different Sensitizing Nanoparticles for Solar Cell Applications
}

\author{
L. F. Dong, Q. Q. Liu, and J. S. Malone
}

Department of Physics, Astronomy, and Materials Science, Missouri State University, Springfield, MO 65897, USA

Alternative energy conversion systems are receiving great attention due to the depletion of fossil fuels and increasing environmental pollution. Solar cells are promising power sources to solve future energy problems because their resources are renewable, non-polluting, and free. However, the high cost of the fabrication of silicon-based solar cells impedes their broad application. One of key strategies to bring down the cost of photovoltaic electricity is to increase the efficiency of the cells. Recently, more and more experiments demonstrated that carbon nanotubes could be used to improve cell efficiency by forming junctions with sensitizing nanoparticles and providing channels for the transport of electrical carriers to the electrodes. In this study, we developed several methods to envelop carbon nanotubes with sensitizing nanoparticles (e.g. $\mathrm{SnO}_{2}$ and $\mathrm{TiO}_{2}$ ), and then studied their structural and photoelectrical properties.

In our experiments, various methods were used to synthesize $\mathrm{SnO}_{2}$ and $\mathrm{TiO}_{2}$ nanoparticles around carbon nanotubes. For instance, $\mathrm{SnO}_{2}$ nanoparticles were prepared by a solution-phase reaction of tin chloride $\left(\mathrm{SnCl}_{4}\right)$ with water. $\mathrm{TiO}_{2}$ nanoparticles were synthesized by using two different precursors: titanium (IV) isopropoxide $\left\{\mathrm{Ti}\left[\mathrm{OCH}\left(\mathrm{CH}_{3}\right)_{2}\right]_{4}\right\}$ and titanium sulfate $\left[\mathrm{Ti}\left(\mathrm{SO}_{4}\right)_{2}\right]$. The obtained nanotube/nanoparticle composites were rinsed several times with DI water, dried at $80{ }^{\circ} \mathrm{C}$ for $12 \mathrm{hrs}$ and $100{ }^{\circ} \mathrm{C}$ for one hour, then at $450{ }^{\circ} \mathrm{C}$ for $30 \mathrm{~min}$. The morphology of the nanoparticles and their distributions along carbon nanotubes were characterized by an FEI Quanta 200 field emission scanning electron microscope (FESEM) [1].

Due to the hydrophobic surface of carbon nanotubes, it is very challenging to directly position nanoparticles onto nanotube surfaces in aqueous solutions [2]. However, our experiments demonstrated that without surface functionalizations for carbon nanotubes, both $\mathrm{SnO}_{2}$ and $\mathrm{TiO}_{2}$ nanoparticles could partially envelope the nanotubes (FIG. 1 and FIG. 3). As given in FIG. 1, $\mathrm{SnO}_{2}$ nanoparticles formed around the nanotubes. The size of the $\mathrm{SnO}_{2}$ nanoparticles ranges from $1 \mathrm{~nm}$ to $6 \mathrm{~nm}$, which is smaller than the diameter of the nanotubes. On the other hand, FIG. 2a shows that there are two types of morphologies for the composite obtained using $\mathrm{Ti}\left(\mathrm{SO}_{4}\right)_{2}$ as a precursor for the synthesis of $\mathrm{TiO}_{2}$ nanoparticles: a twisted mass of carbon nanotubes mixed with $\mathrm{TiO}_{2}$ cylinders. A high magnification image (FIG. 2b) shows that $\mathrm{TiO}_{2}$ nanoparticles aggregated together, and were separated from the carbon nanotubes. Nevertheless, when we used $\mathrm{Ti}\left[\mathrm{OCH}\left(\mathrm{CH}_{3}\right)_{2}\right]_{4}$ as a precursor, $\mathrm{TiO}_{2}$ nanoparticles formed around the carbon nanotubes (FIG. 3a and FIG. $3 \mathrm{~b}$ ), and there were no obvious segregations as shown in FIG. 2. FESEM characterizations indicate that without surface functionalization of carbon nanotubes, nanotubes enveloped with sensitizing nanoparticles could be obtained through the selection of desirable precursors and reaction parameters.

\section{References}

[1] L. F. Dong, R. R. Sanganna Gari, Z. Li, M. M. Craig, and S. F. Hou, Carbon, 48 (2010) 781.

[2] L. F. Dong, C. M. Witkowski, M. M. Craig et al. Nanoscale Research Letters, 4 (2009) 1517.

[3] This research was supported by the National Science Foundation (DMR-0821159), the American Chemical Society Petroleum Research Fund (47532-GB10), and a Summer Faculty Fellowship from Missouri State University. The authors thank B. Muchharla for his help with some experiments. 


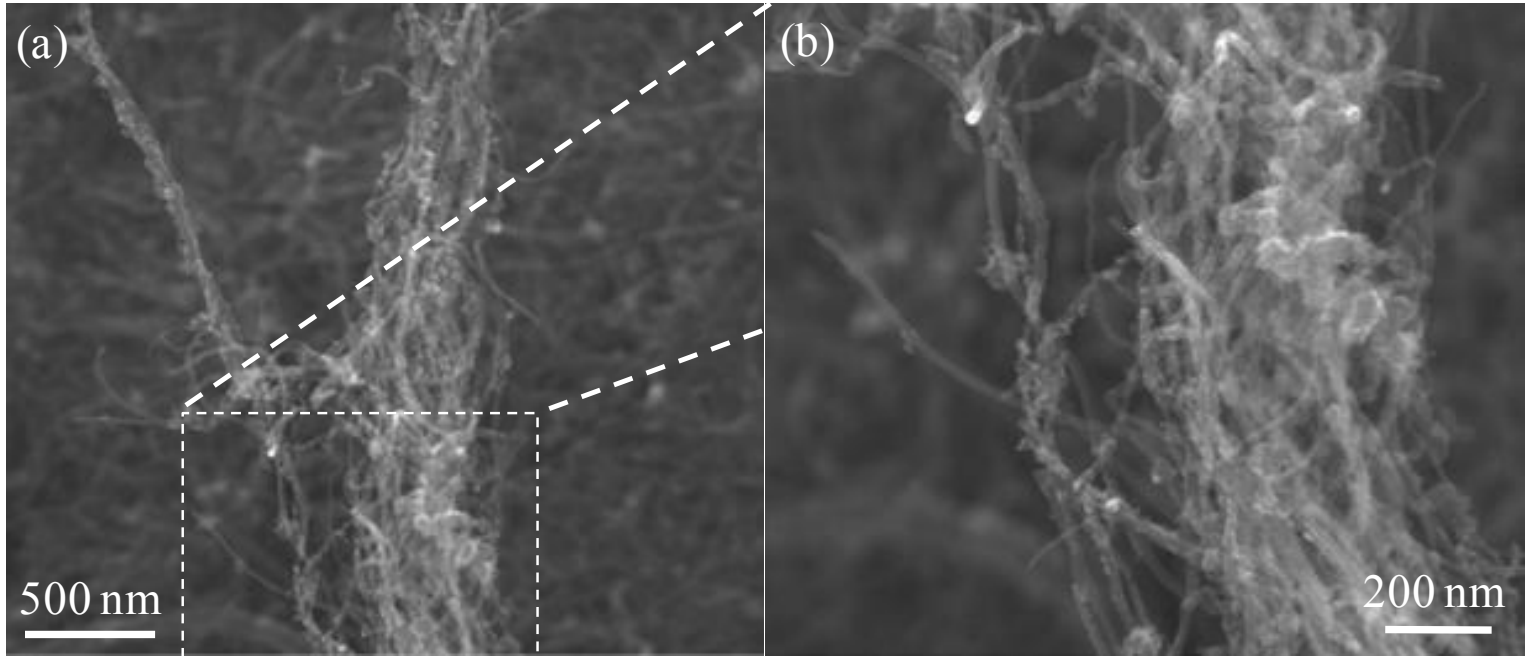

FIG.1. FESEM images of carbon nanotubes enveloped with $\mathrm{SnO}_{2}$ nanoparticles with different magnification: FIG.1b is a close up image of the region indicated by the dash-lined square from FIG.1a.
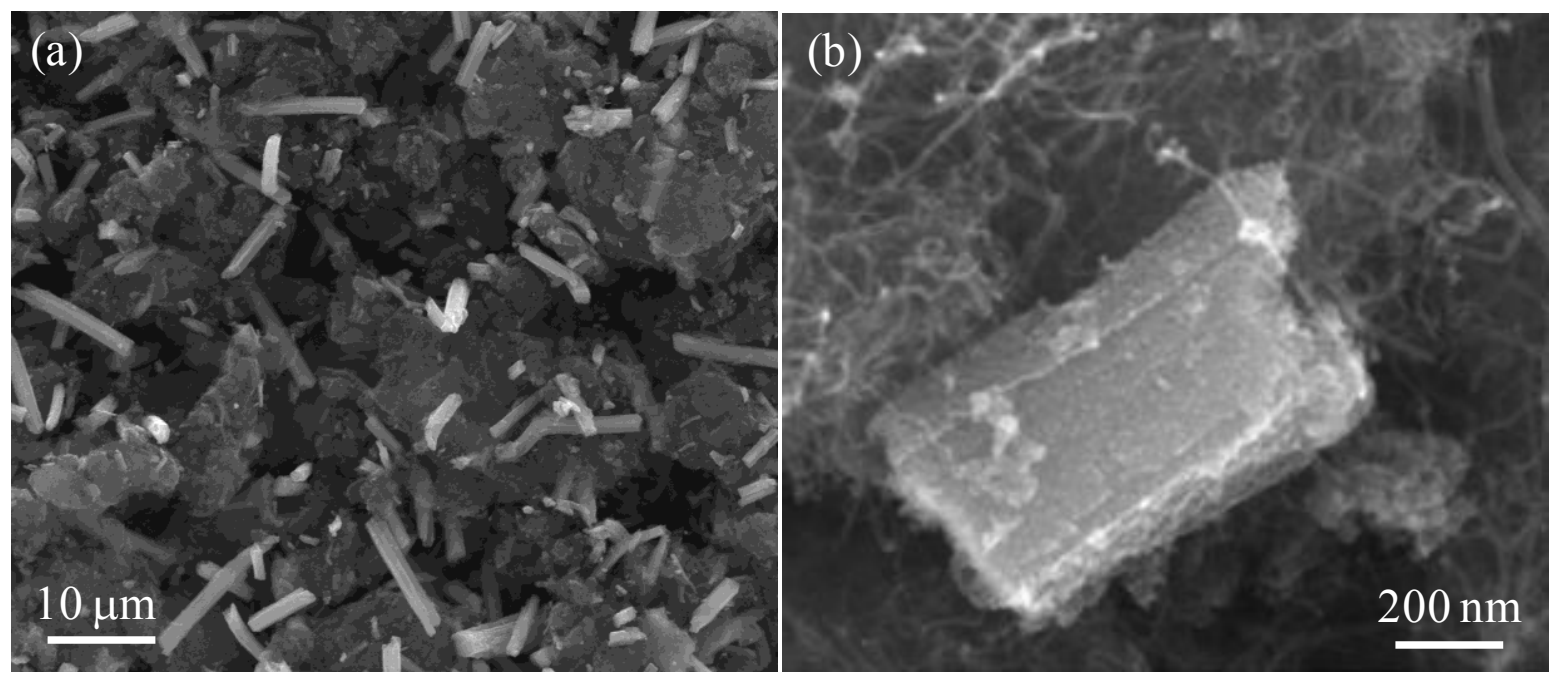

FIG.2. FESEM images of carbon nanotubes enveloped with $\mathrm{TiO}_{2}$ nanoparticles [precursor: $\mathrm{Ti}\left(\mathrm{SO}_{4}\right)_{2}$ ].
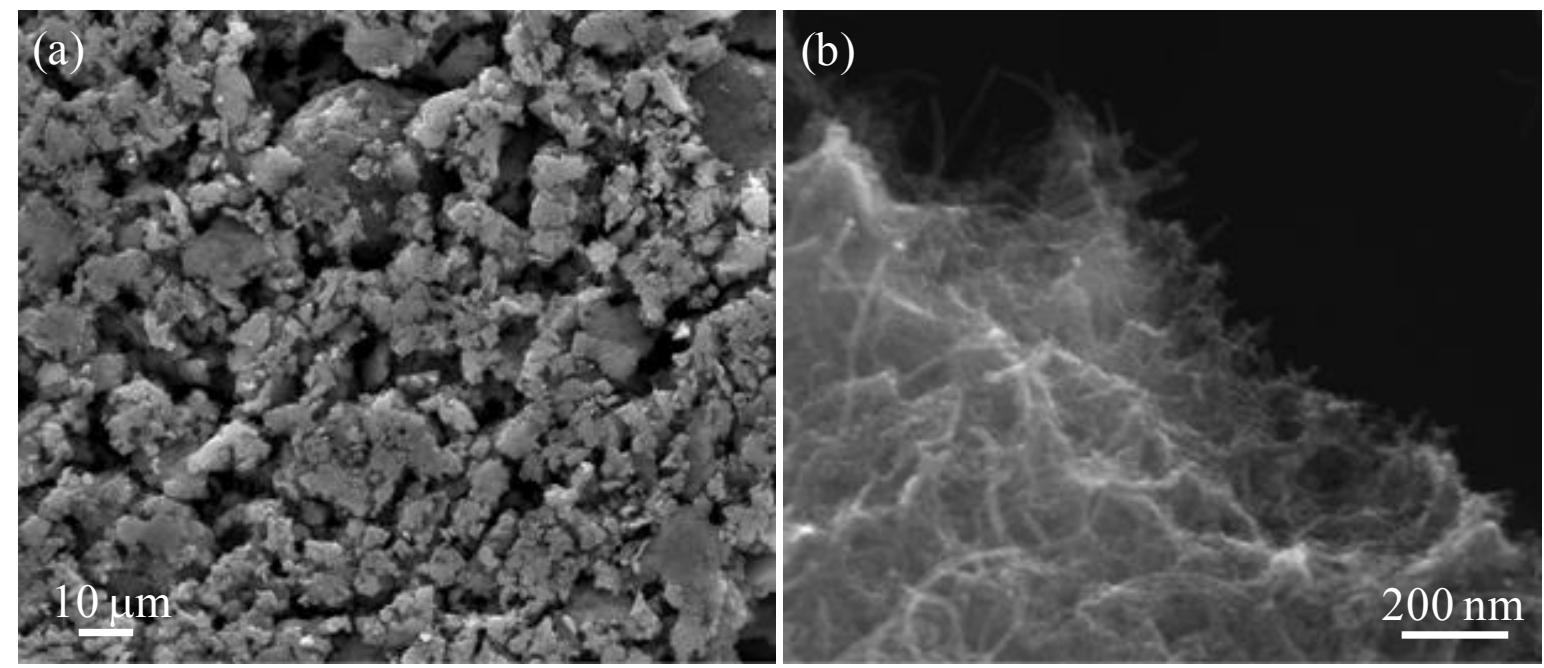

FIG.3. SEM images of carbon nanotubes enveloped with $\mathrm{TiO}_{2}$ nanoparticles $\left\{\right.$ precursor: $\left.\mathrm{Ti}\left[\mathrm{OCH}\left(\mathrm{CH}_{3}\right)_{2}\right]_{4}\right\}$. 